\title{
In vitro Evaluation of Growth Inhibition of Some Common Soil Fungi by Selective and Non-selective Herbicides
}

\author{
Ubogu Monday ${ }^{1,}$, Akponah Ejiro², Ogbaran Dickson Solomon ${ }^{3}$ \\ ${ }^{1}$ Department of Biological Sciences, Federal University of Agriculture Makurdi, Makurdi, Nigeria \\ ${ }^{2}$ Department of Microbiology, Delta State University, Abraka, Nigeria \\ ${ }^{3}$ Department of Engineering, Production Chemicals Nig. Ltd., Warri, Nigeria
}

Email address:

ubomon@yahoo.co.uk (U. Monday)

${ }^{*}$ Corresponding author

\section{To cite this article:}

Ubogu Monday, Akponah Ejiro, Ogbaran Dickson Solomon. In vitro Evaluation of Growth Inhibition of Some Common Soil Fungi by Selective and Non-selective Herbicides. Frontiers in Environmental Microbiology. Vol. 3, No. 1, 2017, pp. 1-8. doi: $10.11648 /$ j.fem.20170301.11

Received: September 6, 2016; Accepted: March 1, 2017; Published: March 24, 2017

\begin{abstract}
The indiscriminate and excessive use of herbicides being witnessed in recent times portends possible danger to environmental and human health. To gage the likely impacts of herbicides onfungal ecosystem services, the influence of three narrow [selective (atrazine, butachlor and 2,4-D)] and two broad [non-selective (glyphosate and paraquat)] spectrum herbicides at various concentrations of $0,0.01,0.1,0.5$ and $1 \% \mathrm{v} / \mathrm{v}$ on the radial mycelial extension growth, mycelial extension growth rate, percentage mycelial growth inhibition and minimum sporulation time of four common soil fungi, Aspergillus niger, A. flavus, Trichoderma viride and Penicillium sp. were investigated on PDA plates for a period of $96 \mathrm{~h}$ at $30 \pm 2^{\circ} \mathrm{C}$ (room temperature). The radial mycelial extension growth of fungi decreased with increased concentrations of the herbicides except for $T$. viride where atrazine did not show any significant difference among all the concentrations tested $(\mathrm{P} \leq 0.05)$. The fastest mycelia extension growth rate for all fungi was recorded in Atrazine at the highest concentration tested, with T. viride being the fastest at $0.44 \mathrm{~mm} \mathrm{~h}^{-1}$. At $1 \% \mathrm{v} / \mathrm{v}$, save for atrazine, all the herbicides inhibited at least $66 \%$ mycelial growth with $2,4-\mathrm{D}$ showing a $100 \%$ inhibition. The minimum sporulation time for all fungi in the presence of the herbicides was $48 \mathrm{~h}$. There was no sporulation in A. flavus and T. viride in presence of paraquat and 2,4-D above $0.1 \% \mathrm{v} / \mathrm{v}$ concentration within the $96 \mathrm{~h}$ of investigation. The results of this study suggest that indiscriminate and excessive use of herbicides could negatively affect ecosystem function.
\end{abstract}

Keywords: Herbicide, Mycelia Growth, Soil Fungi, Sporulation

\section{Introduction}

Globally, the application of herbicides in weed management and control has become ageneral and acceptable practice because of it success and ease of application as against the traditional manual and mechanical process. In Nigeria, there has been an increasing upsurge in the use of herbicides in recent time by peasant and commercial farmers, home owners, private estate developers etc. to control and kill weeds in farms, residential, official and commercial premises. Herbicides have been consistently linked to serious illnesses such as cancer, reproductive problems and neurological diseases, among others [1]. The indiscriminate and excessive use of these herbicidesportends serious danger not only to human health but also agricultural productivity and environmental wellbeing as various groups of soil microorganisms including fungi could be affected.

Fungi are important members of the soil microbial community in terms of their dominance and ecological function. They play critical role in the degradation of organic waste and pollutants, cycling of nutrients in the biogeochemical cycles, and assisting plants in increased nutrient uptake through root-mychorrizae association. They are also a repository of useful antibiotics in medicine, in addition to being important antagonists to some common soil borne plant pathogens [2]. 
The growth inhibition of soil fungi by herbicides therefore could drastically limit these enormous ecological functions with grave environmental consequences. It is on the basis of ascertaining the possible impact of herbicides usage on the growth of fungi in soil that this study was carried out.

\section{Materials and Methods}

\subsection{Isolation and Characterization of Test Fungal Isolates}

The four test fungi employed in this study (Aspergillus niger, A. flavus, Trichoderma viride and Penicillium sp.) were isolated from soil using the soil dilution pour plate method on potato dextrose agar (PDA). Plates were incubated at $30 \pm 2{ }^{\circ} \mathrm{C}$ for five days for the growth of fungi. The pure culture of the test fungal isolates were characterized based on cultural and morphological properties following the fungal identification schemes as described by Rifai, Barnett and Hunter, Humber, and Ellis et al. [3-6].

\subsection{Preparation of Various Concentrations of Herbicides}

In addition to the control, four different concentrations of the herbicides, Atrazine, Butachlor, 2,4-D, Glyphosate and Paraquat were prepared by adding appropriate volume of the respective herbicides (undiluted as constituted and marketed by the manufacturer) to molten PDA at $45^{\circ} \mathrm{C}$ to obtain the following concentrations of herbicides, $0,0.01,0.1,0.5$ and $1 \% \mathrm{v} / \mathrm{v}$.

\subsection{Measurement of Fungal Radial Mycelial Extension Growth on PDA Containing Herbicides}

The radial mycelial extension growth of the test fungi on PDA plates containing the different herbicides at various concentrations was determined by obtaining a $5.0 \mathrm{~mm}$ agar disc inoculum from the edge of actively growing pure culture of the respective test fungi, using a cork borer. With the aid of an inoculating needle, the agar disc inoculum was placed upside down in the centre of a $12 \mathrm{~cm}$ diameter PDA plates containing the various concentrations $(0,0.01,0.1,0.5$ and $1.0 \mathrm{v} / \mathrm{v})$ of the respective herbicides. Culture plates for each herbicide and concentration were prepared in triplicates.

Measurement of the radial mycelia extension growth (in $\mathrm{mm}$ ) of each test fungi on PDA plates was carried out using a graduated meter rule after incubation at room temperature $\left(30 \pm 2{ }^{\circ} \mathrm{C}\right)$ for $96 \mathrm{~h}$. Within the incubation period, test fungi were exposed to alternating $12 \mathrm{~h}$ day lighting and $12 \mathrm{~h}$ darkness by incubating close to laboratory windows.

\subsection{Determination of Percentage Radial Mycelial Extension Growth Inhibition by Herbicides}

The percentage radial mycelial extension growth inhibition of the test fungi at the highest concentration tested $(1 \% \mathrm{v} / \mathrm{v})$ was determined by adapting the method of Zain et al. [7], using the formula:

$\%$ Radial mycelial extension growth inhibition $=\mathrm{D}_{\mathrm{c}}-\mathrm{D}_{\mathrm{f}}$ Dc $\times 100$ (1)

Where $D_{c}=$ Radial mycelial extension growth on PDA without herbicide

$\mathrm{D}_{\mathrm{r}}=$ Radial mycelia extension growth on PDA with herbicide

\subsection{Determination of Fungal Radial Mycelial Extension Growth Rate}

The effect of the various concentrations of herbicides on fungal radial mycelial extension growth rate was determined using the method of Ubogu et al. [8]. The radial mycelial extension growth rate $\left(\mathrm{mm} \mathrm{h}^{-1}\right)$ of each of the test fungi growing on PDA plates containing the various concentrations of the herbicides was determined at the endof the investigation period using the formula:

Radial mycelial extension growth rate $\left(\mathrm{mm} \mathrm{h}^{-1}\right)=$ Total radial growth $(\mathrm{mm}) /$ Total time taken $(\mathrm{h})(2)$

\subsection{Determination of the Effect of Herbicides on the Minimum Sporulation Time of Fungi}

The minimum sporulation time of fungi due the presence of the respective herbicides was determined by observing the fungal growth culture at interval of $24 \mathrm{~h}$ for $96 \mathrm{~h}$ for the presence and appearance of hyphal-bearing spores under low-powered objectives (X 10).

\subsection{Statistical Analysis}

The various data obtained from replicate samples in this study were analyzed using statistical tools such as measure of central tendency (mean), dispersion (standard deviation), Student's t-test and Analysis of Variance (ANOVA) $(\mathrm{P} \leq 0.05)$.

\section{Results}

\subsection{Fungal Radial Mycelial Extension Growth on PDA Containing Herbicides}

The results of this study showed that for A. niger, A. flavus and Penicillium sp., all the concentrations of herbicides employed in this study inhibited theirradial mycelial extensiongrowth as compared to that of the control $(0 \% \mathrm{v} / \mathrm{v})$. Radial mycelial extension growth decreased with increased herbicides concentrations from 0.01 to $1.0 \% \mathrm{v} / \mathrm{v}$ (Fig. 1, 2 and 4). These decreases were least with atrazine and most profound with 2,4-D. At $96 \mathrm{~h}$, from the lowest concentration of 0.01 to the highest of $1.0 \% \mathrm{v} / \mathrm{v}$, atrazine, butachlor, 2,4-D, glyphosate and paraquat recorded radial mycelia extension growth in the range of 34-23.5, 14.3-5.5, 33.0-0.0,22.5-12.5 and 21- $9.0 \mathrm{~mm}$ for $A$. niger; 27.5-17.0, 20.0-7.0, 35.0-0.0, 27.0-11.0 and 25.0-9.0 mm for A. flavus and 16.0-5.5, 15.5$3.5,16.0-0.0,13.5-4.5$ and $15.0-4.0 \mathrm{~mm}$ for Penicillium sp. as compared to the control with $36.9 ; 35.7$ and $17.3 \mathrm{~mm}$ growth respectively. The degree of radial mycelial extension growth of A. niger, A. flavus and Penicillium sp., varied significantly with the type of herbicide irrespective of its selective or non-selectiveness $(\mathrm{P} \leq 0.05)$.

However in the case of $T$. viride, the radial mycelial extension growth of the fungi also decreased with increased 
concentrations of the herbicides from 0.01 to $1.0 \% \mathrm{v} / \mathrm{v}$ with the exception of atrazine where there was no significant difference in the radial mycelialextension growth of the organismin the control as compared to all other concentrations tested (Fig. 3). The lowest radial mycelia extension growth of the fungi occurred with paraquat which was followed by $2,4-\mathrm{D}$. At concentration as low as $0.1 \% \mathrm{v} / \mathrm{v}$, the growth of the organism was completely stopped by paraquat. The range of the radial mycelial extension growth of $T$. viride by atrazine, butachlor, 2,4-D, glyphosate and paraquat at 0.01 and $1.0 \% \mathrm{v} / \mathrm{v}$ were $42.5-42.5,34.5-7.0,42.5$ $0.0,42.5-8.5$ and $42.5-0.0 \mathrm{~mm}$ respectively as compared to the control with $42.5 \mathrm{~mm}$ growth at $96 \mathrm{~h}$. Similarly, the degree of radial mycelial extension growth of $T$. viridevaried significantly with the type of herbicide irrespective of its selective or non-selectiveness $(\mathrm{P} \leq 0.05)$.

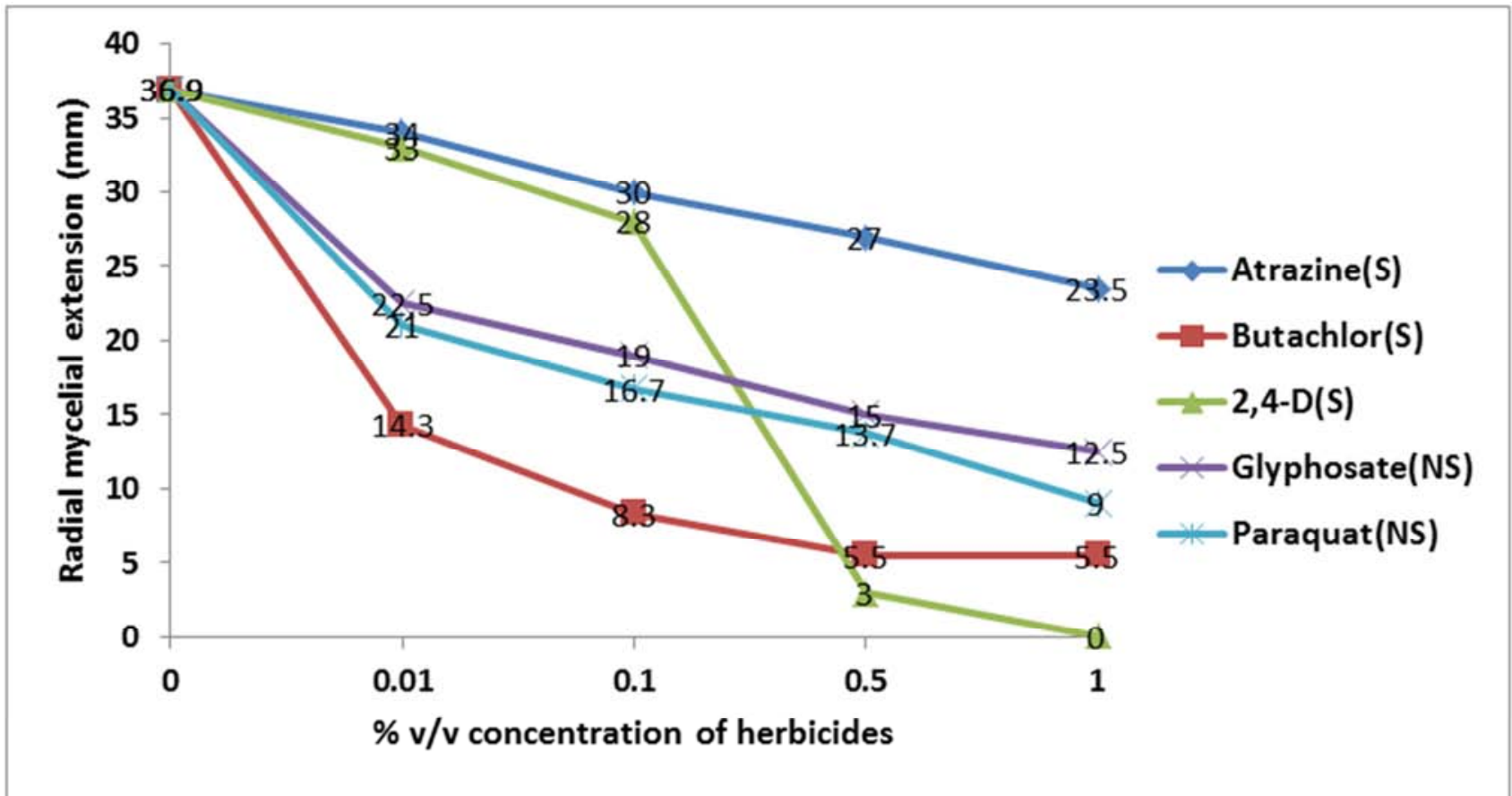

Figure 1. Radial mycelial extension growth of A. niger at various concentrations of herbicides.

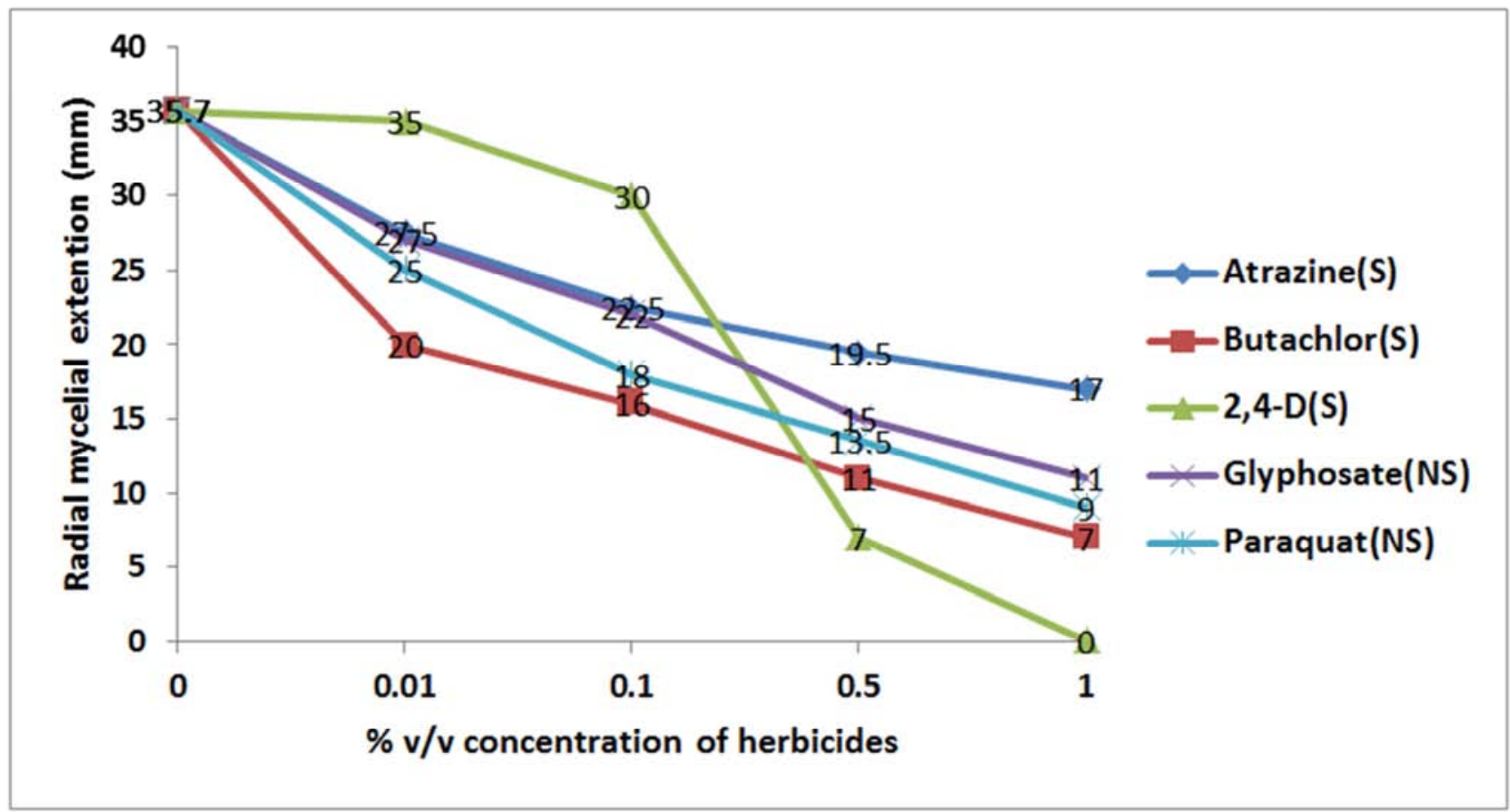

Figure 2. Radial mycelia extension growth of A. flavus at various concentrations of herbicides. 


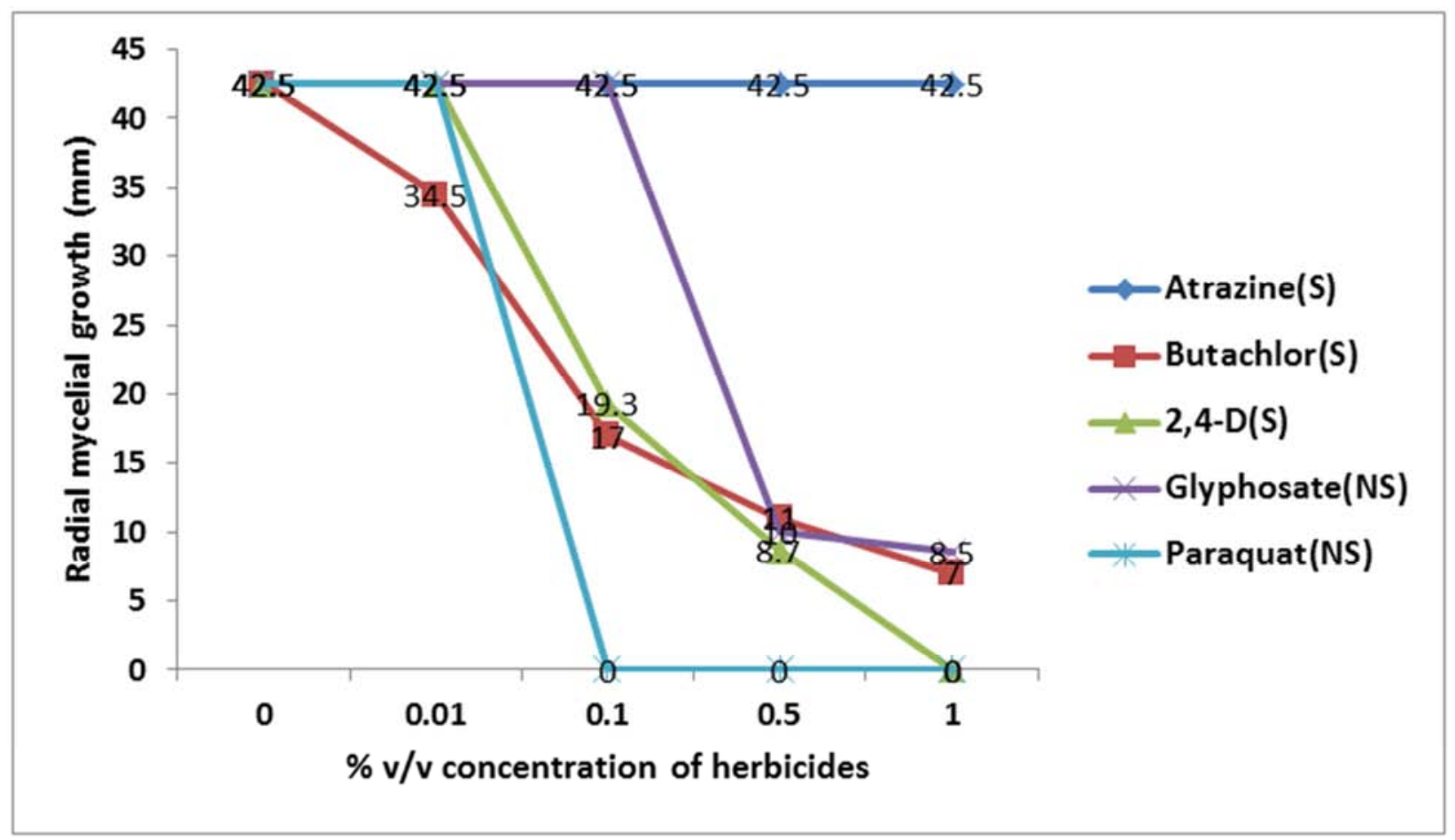

Figure 3. Radial mycelial extension growth of T. viride at various concentrations of herbicides.

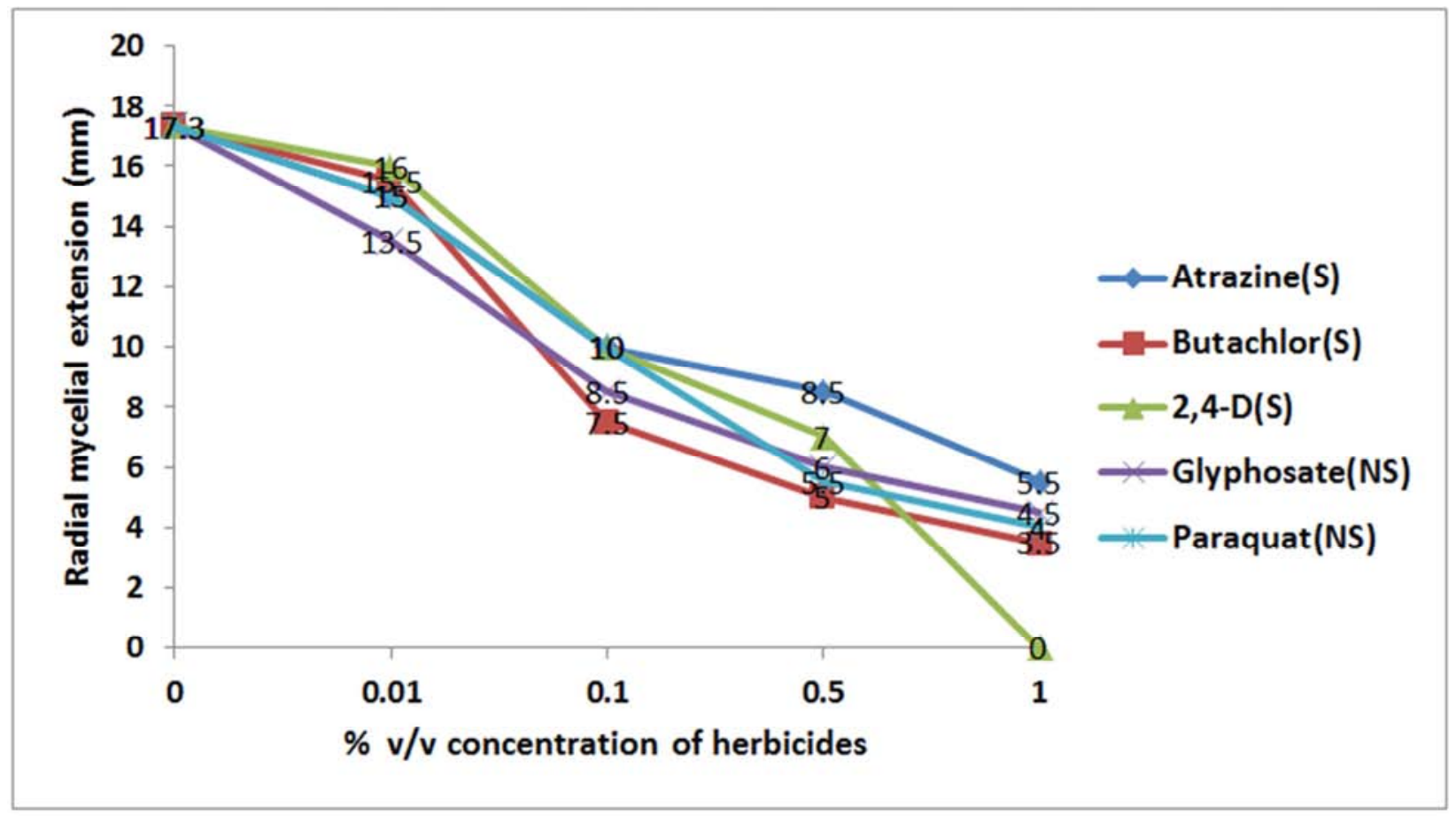

Figure 4. Radial mycelial extension growth of Penicillium sp. at various concentrations of herbicides.

\subsection{Fungal Radial Mycelial Extension Growth Rate in the Presence of Herbicides}

With the exception of atrazine which did show any effect on $T$. viride as compared to the control, the radial mycelial extension growth rate of all the fungi varied significantly with the type of herbicide and the concentration tested in this study $(\mathrm{P} \leq 0.05)$ (Table 1,2, 3 and 4$)$. The radial mycelial extension growth rate decreased with increased concentration.
For A. niger, A. flavus and Pencillium sp., with the exception of the control where radial mycelial extension growth rate were $0.38,0.35$ and $0.18 \mathrm{~mm} \mathrm{~h}^{-1}$, atrazine produced the fastest radial mycelial extension growth rate of $0.35,0.29$ and $0.17 \mathrm{~mm} \mathrm{~h}^{-1}$ at the lowest concentration of $0.01 \% \mathrm{v} / \mathrm{v}$, while butachlor, $0.06,0.08$ and $0.04 \mathrm{~mm} \mathrm{~h}^{-1}$ as the slowest at the highest concentration of $1.0 \% \mathrm{v} / \mathrm{v}$ respectively.

On the contrary, for $T$. viride, with exception of butachlor 
with $0.36 \mathrm{~mm} \mathrm{~h}^{-1}$, the radial mycelial extension growth rate for all the other herbicides were the same with that of the control $\left(42.5 \mathrm{~mm} \mathrm{~h}^{-1)}\right.$ at the lowest concentration of $0.01 \%$ $\mathrm{v} / \mathrm{v}$, while butachlor produced the slowest growth rate of 0.07 $\mathrm{mm} \mathrm{h}^{-1}$ at the highest concentration of $1.0 \% \mathrm{v} / \mathrm{v}$.
However, there was no growth at all among the fungi tested in the presence of 2,4-D. Furthermore, paraquat in addition, also did not produced growth for $T$. viride at $1.0 \%$ $\mathrm{v} / \mathrm{v}$ concentration.

Table 1. Mycelial extension growth rate $\left(\mathrm{mm} \mathrm{h}^{-1}\right)$ of $A$. niger in the presence of herbicides.

\begin{tabular}{|c|c|c|c|c|c|}
\hline Herbicide & Mycelial & Extension & Growth Rate & $\left(\mathrm{mm} \mathrm{h}^{-1}\right)$ & \\
\hline & & Concentration & $(\% \mathrm{v} / \mathrm{v})$ & & \\
\hline & 0 & 0.01 & 0.1 & 0.5 & 1.0 \\
\hline Atrazine (S) & $0.38 \pm 0.09^{\mathrm{a}}$ & $0.35 \pm 0.01^{\mathrm{b}}$ & $0.31 \pm 0.03^{\mathrm{c}}$ & $0.28 \pm 0.01^{\mathrm{c}}$ & $0.24 \pm 0.01^{\mathrm{d}}$ \\
\hline Butachlor (S) & $0.38 \pm 0.09^{\mathrm{a}}$ & $0.15 \pm 0.01^{\mathrm{b}}$ & $0.09 \pm 0.00^{\mathrm{c}}$ & $0.06 \pm 0.00^{d}$ & $0.06 \pm 0.00^{\mathrm{d}}$ \\
\hline 2,4-D (S) & $0.38 \pm 0.09^{\mathrm{a}}$ & $0.34 \pm 0.01^{\mathrm{b}}$ & $0.29 \pm 0.00^{\mathrm{c}}$ & $0.03 \pm 0.00^{\mathrm{d}}$ & 0.0 \\
\hline Glyphosate(NS) & $0.38 \pm 0.9^{\mathrm{a}}$ & $0.23 \pm 0.01^{\mathrm{b}}$ & $0.20 \pm 0.01^{\mathrm{b}}$ & $0.16 \pm 0.01^{\mathrm{c}}$ & $0.13 \pm 0.01^{\mathrm{d}}$ \\
\hline Paraquat (NS) & $0.38 \pm 0.09^{\mathrm{a}}$ & $0.22 \pm 0.01^{\mathrm{b}}$ & $0.17 \pm 0.01^{\mathrm{c}}$ & $0.14 \pm 0.01^{\mathrm{d}}$ & $0.09 \pm 0.01^{\mathrm{e}}$ \\
\hline
\end{tabular}

Key:*Values with the same superscript alphabet in the same row did not differ significantly $(\mathrm{P} \leq 0.05)$

S- Selective Herbicide

NS-Non-Selective Herbicide

Table 2. Mycelial extension growth rate $\left(\mathrm{mm} \mathrm{h}^{-}{ }^{1}\right)$ of $A$. flavus in the presence of herbicides.

\begin{tabular}{|c|c|c|c|c|c|}
\hline Herbicide & Mycelial & Extension & Growth Rate & $\left(\mathrm{mm} \mathrm{h}^{-1}\right)$ & \\
\hline & & Concentration & $(\% \mathrm{v} / \mathrm{v})$ & & \\
\hline & 0 & 0.01 & 0.1 & 0.5 & 1.0 \\
\hline Atrazine (S) & $0.35 \pm 0.01^{\mathrm{a}}$ & $0.29 \pm 0.01^{\mathrm{b}}$ & $0.23 \pm 0.00^{\mathrm{c}}$ & $0.20 \pm 0.01^{\mathrm{d}}$ & $0.18 \pm 0.01^{\mathrm{d}}$ \\
\hline Butachlor (S) & $0.35 \pm 0.01^{\mathrm{a}}$ & $0.21 \pm 0.00^{\mathrm{b}}$ & $0.17 \pm 0.01^{\mathrm{c}}$ & $0.11 \pm 0.00^{\mathrm{d}}$ & $0.08 \pm 0.01^{\mathrm{e}}$ \\
\hline 2,4-D (S) & $0.35 \pm 0.01^{\mathrm{a}}$ & $0.35 \pm 0.01^{\mathrm{a}}$ & $0.31 \pm 0.05^{\mathrm{b}}$ & $0.08 \pm 0.01^{\mathrm{c}}$ & 0.0 \\
\hline Glyphosate(NS) & $0.35 \pm 0.01^{\mathrm{a}}$ & $0.28 \pm 0.01^{\mathrm{b}}$ & $0.23 \pm 0.01^{\mathrm{c}}$ & $0.16 \pm 0.01^{\mathrm{d}}$ & $0.12 \pm 0.01^{\mathrm{e}}$ \\
\hline Paraquat (NS) & $0.35 \pm 0.01^{\mathrm{a}}$ & $0.26 \pm 0.00^{\mathrm{b}}$ & $0.19 \pm 0.00^{\mathrm{c}}$ & $0.14 \pm 0.01^{\mathrm{d}}$ & $0.09 \pm 0.02^{\mathrm{e}}$ \\
\hline
\end{tabular}

*Values with the same superscript alphabet in the same row did not differ significantly $(\mathrm{P} \leq 0.05)$

Table 3. Mycelial extension growth rate $\left(\mathrm{mm} \mathrm{h}^{-1}\right)$ of T. viride in the presence of herbicides.

\begin{tabular}{|c|c|c|c|c|c|}
\hline Herbicide & Mycelial & Extension & Growth Rate & $\left(\mathrm{mm} \mathrm{h}^{-1}\right)$ & \\
\hline & & Concentration & $(\% \mathrm{v} / \mathrm{v})$ & & \\
\hline & 0 & 0.01 & 0.1 & 0.5 & 1.0 \\
\hline Atrazine (S) & $0.44 \pm 0.00^{\mathrm{a}}$ & $0.44 \pm 0.00^{\mathrm{a}}$ & $0.44 \pm 0.00^{\mathrm{a}}$ & $0.44 \pm 0.01^{\mathrm{a}}$ & $0.44 \pm 0.00^{\mathrm{a}}$ \\
\hline Butachlor (S) & $0.44 \pm 0.00^{\mathrm{a}}$ & $0.36 \pm 0.01^{\mathrm{b}}$ & $0.18 \pm 0.01^{\mathrm{c}}$ & $0.11 \pm 0.02^{\mathrm{d}}$ & $0.07 \pm 0.02^{\mathrm{e}}$ \\
\hline 2,4-D (S) & $0.44 \pm 0.00^{\mathrm{a}}$ & $0.44 \pm 0.00^{\mathrm{a}}$ & $0.20 \pm 0.02^{b}$ & $0.09 \pm 0.03^{c}$ & 0.0 \\
\hline Glyphosate(NS) & $0.44 \pm 0.00^{\mathrm{a}}$ & $0.44 \pm 0.00^{\mathrm{a}}$ & $0.44 \pm 0.00^{\mathrm{a}}$ & $0.10 \pm 0.01^{\mathrm{c}}$ & $0.09 \pm 0.00^{\mathrm{c}}$ \\
\hline Paraquat (NS) & $0.44 \pm 0.00^{\mathrm{a}}$ & $0.44 \pm 0.00^{\mathrm{a}}$ & 0.0 & 0.0 & 0.0 \\
\hline
\end{tabular}

*Values with the same superscript alphabet in the same row did not differ significantly $(\mathrm{P} \leq 0.05)$

Table 4. Mycelial extension growth rate $\left(\mathrm{mm} \mathrm{h}^{-1}\right)$ of Penicillium sp. in the presence of herbicides.

\begin{tabular}{|c|c|c|c|c|c|}
\hline Herbicide & Mycelial & Extension & Growth Rate & $\left(\mathrm{mm} \mathrm{h}^{-1}\right)$ & \\
\hline & & Concentration & $(\% \mathrm{v} / \mathrm{v})$ & & \\
\hline & 0 & 0.01 & 0.1 & 0.5 & 1.0 \\
\hline Atrazine (S) & $0.18 \pm 0.03^{\mathrm{a}}$ & $0.17 \pm 0.02^{\mathrm{a}}$ & $0.11 \pm 0.02^{\mathrm{b}}$ & $0.09 \pm 0.00^{\mathrm{c}}$ & $0.06 \pm 0.00^{\mathrm{d}}$ \\
\hline Butachlor (S) & $0.18 \pm 0.03^{\mathrm{a}}$ & $0.16 \pm 0.03^{\mathrm{a}}$ & $0.08 \pm 0.01^{\mathrm{b}}$ & $0.05 \pm 0.00^{\mathrm{c}}$ & $0.04 \pm 0.00^{\mathrm{c}}$ \\
\hline 2,4-D (S) & $0.18 \pm 0.03^{\mathrm{a}}$ & $0.17 \pm 0.00^{\mathrm{a}}$ & $0.11 \pm 0.00^{\mathrm{b}}$ & $0.07 \pm 0.02^{\mathrm{c}}$ & 0.0 \\
\hline Glyphosate(NS) & $0.18 \pm 0.03^{\mathrm{a}}$ & $0.14 \pm 0.02^{\mathrm{b}}$ & $0.09 \pm 0.02^{\mathrm{c}}$ & $0.06 \pm 0.01^{\mathrm{d}}$ & $0.05 \pm 0.00^{\mathrm{d}}$ \\
\hline Paraquat (NS) & $0.18 \pm 0.03^{\mathrm{a}}$ & $0.16 \pm 0.00^{\mathrm{a}}$ & $0.11 \pm 0.00^{\mathrm{b}}$ & $0.06 \pm 0.00 \mathrm{c}$ & $0.04 \pm 0.01^{\mathrm{c}}$ \\
\hline
\end{tabular}

*Values with the same superscript alphabet in the same row did not differ significantly $(\mathrm{P} \leq 0.05)$

\subsection{Percentage Radial Mycelial Extension Growth Inhibition by Herbicides}

The percentage radial mycelial extension growth inhibition of the tested fungi at $1 \% \mathrm{v} / \mathrm{v}$, varied significantly with the type of herbicide irrespective of its selective or nonselectiveness $(\mathrm{P} \leq 0.05)$ (Fig. 5). While the presence of atrazine did not show any form of radial mycelial extension growth inhibition of $T$. viride, the presence of paraquat resulted in $100 \%$ inhibition. In addition to $T$. viride, the presence of 2,4-D also resulted in $100 \%$ growth inhibition of the three other tested fungi at $1 \% \mathrm{v} / \mathrm{v}$ concentration. Among the herbicides evaluated, Atrazine produced the lowest percentage radial mycelial extension growth inhibition, while 2,4-D produced the highest percentage growth inhibition of the tested fungi. Save for atrazine, the presence of all the other herbicides evaluated resulted in over $66 \%$ radial mycelial extension growth inhibition of all the tested fungi. 


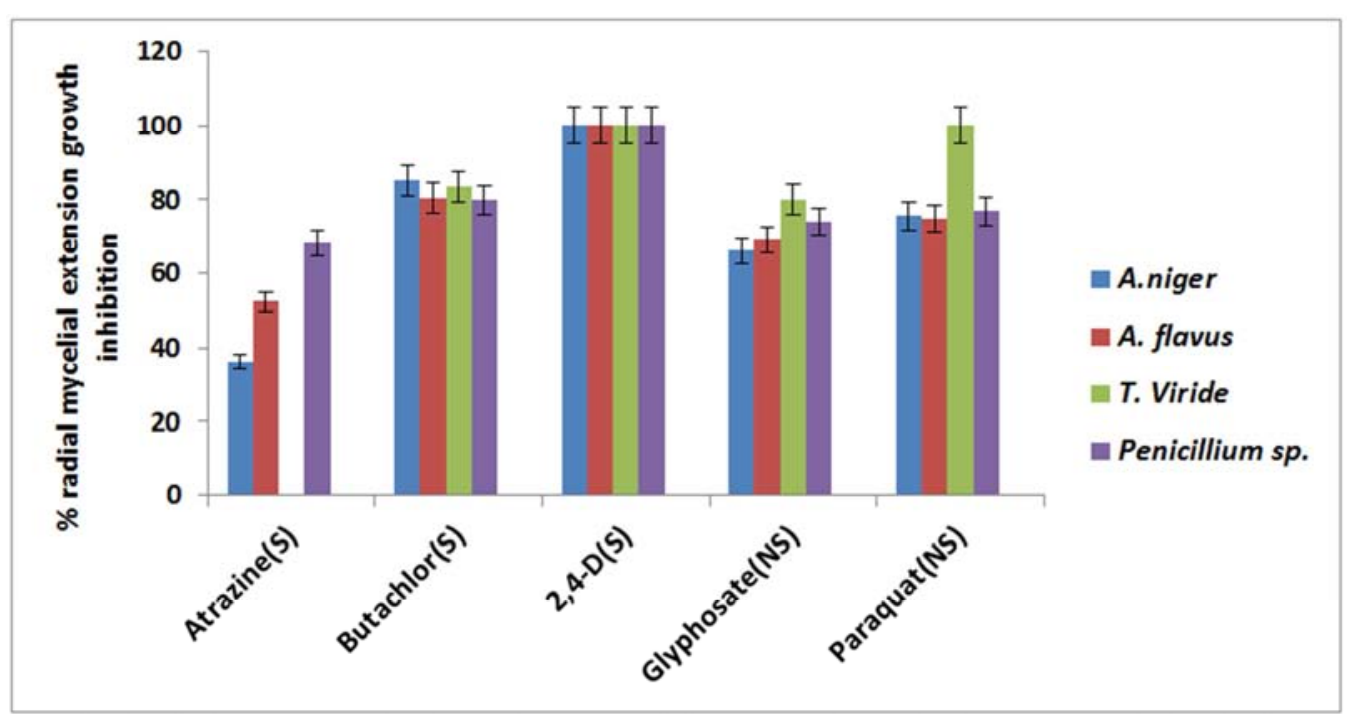

Figure 5. Percentage radial mycelial extension growth inhibition of test fungi by herbicides at $1 \%$ v $/ v$ concentrations.

\subsection{Effect of Herbicides at Various Concentrations on Fungal Minimum Sporulation Time}

The results of this study showed that the minimum sporulation time for the test fungi in the presence of the various herbicideswas $48 \mathrm{~h}$ wherever sporulation occurred including the control (Table 5). However, sporulation did not occur in the presence of $2,4-\mathrm{D}$ at $1.0 \% \mathrm{v} / \mathrm{v}$ for all the fungi, and for $T$. viridein the presence of paraquat beyond $0.01 \%$ $\mathrm{v} / \mathrm{v}$ concentration due to complete absence of any form of growth. On the other hand, in addition to the absence of sporulation in A. flavus at $1.0 \% \mathrm{v} / \mathrm{v}$ in the presence of paraquat,2,4-D and paraquat also prevented the sporulation of $A$. flavus and $T$. viride at 0.1 and $0.5 \% \mathrm{v} / \mathrm{v}$ concentrations (where growth occurred) within the $96 \mathrm{~h}$ of the investigation.

Table 5. Effect of herbicides at various concentrations on fungal minimum sporulation time.

\begin{tabular}{|c|c|c|c|c|}
\hline Herbicide Con.(\% v/v) & Minimum & Sporulation & Time (Hour) & \\
\hline & A.niger & A. flavus & T. viride & Penicillium sp. \\
\hline Control & ++ & ++ & ++ & ++ \\
\hline \multicolumn{5}{|l|}{ Atrazine } \\
\hline 0.01 & ++ & ++ & ++ & ++ \\
\hline 0.1 & ++ & ++ & ++ & ++ \\
\hline 0.5 & ++ & ++ & ++ & ++ \\
\hline 1.0 & ++ & ++ & ++ & ++ \\
\hline \multicolumn{5}{|l|}{ Butachlor } \\
\hline 0.01 & ++ & ++ & ++ & ++ \\
\hline 0.1 & ++ & ++ & ++ & ++ \\
\hline 0.5 & ++ & ++ & ++ & ++ \\
\hline 1.0 & ++ & ++ & ++ & ++ \\
\hline \multicolumn{5}{|l|}{ 2,4-D } \\
\hline 0.01 & ++ & ++ & ++ & ++ \\
\hline 0.1 & ++ & - & - & ++ \\
\hline 0.5 & ++ & - & - & ++ \\
\hline 1.0 & ++ & ++ & ++ & ++ \\
\hline \multicolumn{5}{|l|}{ Glyphosate } \\
\hline 0.01 & ++ & ++ & ++ & ++ \\
\hline 0.1 & ++ & ++ & ++ & ++ \\
\hline 0.5 & ++ & ++ & ++ & ++ \\
\hline 1.0 & ++ & ++ & ++ & ++ \\
\hline \multicolumn{5}{|l|}{ Paraquat } \\
\hline 0.01 & ++ & ++ & ++ & ++ \\
\hline 0.1 & ++ & - & 0 & ++ \\
\hline 0.5 & ++ & - & 0 & ++ \\
\hline 1.0 & ++ & - & 0 & ++ \\
\hline
\end{tabular}

Key: $+=24 \mathrm{~h}$

$++=48 \mathrm{~h}$

$+++=96 \mathrm{~h}$

$-=$ No sporulation

$0=$ No growth 


\section{Discussion}

With the exception of atrazine which did not inhibit the radial mycelial growth of $T$. viride at all the tested concentrations, all the herbicides investigated in this study showed a progressive reduction of mycelial growth of the tested fungi as the concentrations of the herbicides increased when compared to the control. The extent of radial mycelial growth reduction in the presence of the herbicides varied with fungal species and the type of herbicide irrespective of whether it is a narrow (selective) or broad (non-selective) spectrum herbicide. Previous reports also lend credence to the findings in this work. The effects of herbicides on fungal growth have been shown to be specific and dependent on the type, dose, microbial species and environmental conditions [9, 10]. Pasaribu et al. [11], reported differential responses of the mycorrhiza fungus Glomus mosseae to alachor and glyphosate with the fungus being more sensitive to alachor. While the herbicides did not affect the external hyphal length, there was increasing reduction ofinternal hyphal growth with increasing rates of alachlor application as against glyphosate which never did. Furthermore, while investigating the effect of the herbicides pretilachlor, 2,4-D, paraquat, glyphosate and anilofos on the mycelia growth of Fusarium pallidoroseum, Praveena et al. [12], reported that with the exception of pretilachlor which did not affect the mycelia growth of the fungus, all the other herbicides reduced the mycelia growth of the fungus with increased concentrations, and the degree of reduction varied with the type of herbicide. Similarly, Zain et al. [7], evaluatedmycelia growth inhibition and influence of exposure periods of paraquat, glufosinate-ammonium, glyphosate and metsulfuron-methyl onAspergillus sp., Penicillium sp. and Mucor sp. and reported that these varied with fungal species, herbicides and their rate of application.

To understand fungal capacity to colonize and settle on a particular substrate, it is important to study their growth rate [13]. Of all the herbicides employed in this study, 2,4-D appeared to be the most potent as it not only reduced the radial mycelial growth rate with increased concentration like the other herbicides, but resulted in a $100 \%$ mycelial growth inhibition of all the fungi at $1 \% \mathrm{v} / \mathrm{v}$. However, on the other extreme, atrazine was the least potent of the herbicides to the point that it completely failed to arrest the mycelial growth of $T$. viride even at the highest concentration tested. This corroborate the findings of Rodriguez-Kahana et al. [14], who had earlier reported that all the concentrations of atrazine tested, 8, 20, 40 and $80 \mathrm{ppm}$ enhanced $T$. viride growth; and that of Cupul et al. [13], who reported that although, atrazine inhibited the mycelial growth rate of all the tested macrofungi (Cymatadoderma elegans, Daedalea elegans, Pleurotus djamor, Pleurotus sp., Pycnoporus sanguineus and Trametes maxima), non reached $100 \%$ under the tested doses(468, 937, 1875 and $\left.3750 \mathrm{mgL}^{-1}\right)$ with some fungi not inhibited at all at lower doses, and concluded that moderate doses of atrazine are not toxicto the fungi. Variation in the degree of mycelial growth inhibition may be attributed to the differential toxicity of the herbicides arising from their chemical composition and the degradative capacity of the respective fungi. Fungi may either degrade herbicides or get affected adversely by their presence depending on the type of herbicide $[15,16]$.

In this study, the minimum sporulation time of the test fungi in the presence of the herbicides was $48 \mathrm{~h}$ wherever growth occurred. While there was mycelialgrowth, there was no sporulation in A. flavus at $1.0 \% \mathrm{v} / \mathrm{v}$ in the presence of paraquat. Similarly, sporulation also failed to occur even when there were mycelial extension growth in the presence of paraquat and 2,4-D for A. flavus and T. viride at 0.1 and $0.5 \% \mathrm{v} / \mathrm{v}$ concentrations within the $96 \mathrm{~h}$ of this investigation. Variation in fungal sporulation in the presence of different herbicides and concentrations observed in this work is in agreement with what have been earlier reported. Direct effects of herbicides on fungal sporulation have been found to be variable and often species and dosage dependent [17]. Ray and Pandey [18], reported that while glyphosate stimulated sporulation of Alternaria alternate, 2-4-D inhibited same. Sporulation of $F$. pallidoroseum have also been shown to be inhibited by $2,4-\mathrm{D}$ (at 1.0 and $0.25 \mathrm{~kg}$ ai ha-1) and paraquat (at 0.75 and $0.19 \mathrm{~kg}$ ai ha-1) [12]. While investigating the fungistatic effect of lidocaine, a potent local anaesthetic on the growth and sporulation of A. niger, Jaiswal et al. [19], reported delayed sporulation of the fungi by a day from 0.2 to $1.0 \%$ as compared to $0.1 \%$ concentration.

Herbicides have been shown to influence fungal competitive colonization of substrates. A change in the patterns of colonization of substrates by microorganisms may affect the rate at which these substrates are subsequently decomposed [20].

\section{Conclusion}

The results of this study clearly indicate the negative effects of herbicides on the growth of soil fungal community. The growth inhibition of soil fungi is therefore most likely to increase the persistence of herbicides and other organic compounds in the environment.

\section{References}

[1] Ontario College of Family Physicians (2004). Pesticides Literature Review. Toronto: Ontario College of Family Physicians, 2004. Print.

[2] Ikediugwu, F.E.O. and Ubogu, M. (2012). Root Zone Microflora is Responsible for Suppressiveness of the White Root Rot Disease in Akwete Rubber Plantations. $J$. PlantPathol. Microbiol. 3: 151-156.

[3] Rifai, M. A. (1969). A Revision of the Genus Trichoderma. Commonwealth MycologicalInstitute Key Survey, England.

[4] Barnett, H. L. and Hunter, B. B. (1972). Illustrated Genera of Imperfect Fungi. Third edit. New York: Burgess, 225 p. ISBN 978-08-087-0266-5. 
[5] Humber, R. A. (2005). Entomopathogenic Fungal Identification. USDA-ARS PlantProtection Research Unit US Plant, Soil \& Nutrition Laboratory. Tower Road Ithaca, NY14853-2901, USA.

[6] Ellis, D., Davis, S., Alexiou, H., Handke, R., Bartley, R. (2007). Descriptions of MedicalFungi.2nd Edition. Mycology Unit Women's and Children's Hospital North Adelaide5006 Australia.

[7] Zain, N. M. M., Mohamad, R. B., Sijam, K. Morshed, M. M. and Awang, Y. (2013). Effectofselected herbicides in vitro and in soil on growth and development of soil fungi fromoil palm plantation. Int. J. Agric. Biol. 15: 820-826.

[8] Ubogu, M., Akponah, E. and Ejukonemu, F. E. (2015). Growth assessment of threecommon soil fungi (Trichoderma viride, Aspergillus niger and Penicillium sp.) onformulated culture medium. Mycopath. 13 (2): 71-80.

[9] Bollen, W. B. (1961). Interaction between pesticides and soil microorganisms. Annu. Rev. Microbiol. 15: 69-92.

[10] Hattori, T. (1973). Microbial Life in the Soil: An Introduction. Marcel Dekker, NewYork USA.

[11] Pasaribu, A., Mohamad, R. B., Hashim, A., Rahman, Z. A., Omar, D. and Morshed, M. M. (2013). Effect of herbicide on sporulation and infectivity of vesicular arbuscularmycorrhizal (glomus mosseae) symbiosis with peanut plant. Journal of Animal \& PlantSciences. 23 (6): 1671-1678.

[12] Praveena, R., Naseema, A. and George, S. (2007). Effect of herbicides on Fusariumpallidoroseum - a potential biocontrol agent of water hyacinth [Eichhornia crassipes (Mart.) Solms]. Journal of Tropical Agriculture. 45 (1-2): 55-57.
[13] Cupula, W. C., Abarcaa, G. H., Vázquezb, R. R., Salmonesa, D. Hernándeza, R. G., Gutiérrezc, E. A. (2014). Response of lignolytic macrofungi to herbicide atrazine: dose-response bioassay. Revista Argentina de Microbiologia. 46 (4): 348-357.

[14] Rodriguez-Kabana, R., and Curl, E. A., Funderburk, H. H., Jr. (1967). Effect of atrazineongrowth response of Sclerotium rolfsii and Trichoderma viride. Can. J. Microbiol. 13: 13431349 .

[15] Abdel-Fattah, H. M., Abdel-Kader, M. I. A. and Hamida, S. (1983). Selective effects oftwo triazine herbicides on Egyptian soil fungi. Mycopathologia. 82: 143-151.

[16] Abdel-Mallek, A. Y. and Moharram, A. M. (1986). Effect of the herbicide ametryn oncellulose-decomposing fungi in Egyptian soil. Folia Microbiologica. 31: 375-381.

[17] Dehnet, B., Bodmer, M. and Schuepp, H. (1990). Influence of herbicides on VAmycorrhizal propagation in soil. Symbiosis. 9: 223-227.

[18] Ray, P. S. and Pandey, A. K. (2008). Deleterious effect of herbicides on water hycainthbiocontrol of agents Neochetina bruchi and Alternaria alternate. Biocontrol Scienceand Technology. 18 (5): 517-526.

[19] Jaiswal, S., Sawhney, N. and Sawhney, S. (2005). In vitro inhibition of growth and sporulation in Aspergillus niger by lidocaine - a local anaesthetic agent. Current Science. 88 (1): 152-154.

[20] Wilkinson, V. and Lucas, R. L. (1969). Influence of herbicides on the competitiveability of fungi to colonize plant tissues. New Phytol. 68: 701-708. 